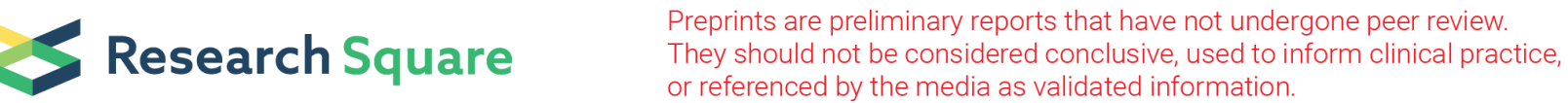

\section{Fully integrated, all-stretchable epidermal electronics with digital electrochromic display for rapid electrochemical sensing}

Lu Yin

University of California San Diego

Mengzhu Cao

University of California San Diego

Kyeong Nam Kim

University of California San Diego

Muyang Lin

University of California San Diego

Juliane Sempionatto

University of California San Diego

Jialu Yu

University of California San Diego

Jong-Min Moon

University of California San Diego

Alexander Trifonov

University of California San Diego

Fangyu Zhang

University of California, San Diego https://orcid.org/0000-0002-6522-5230

Hongjie Hu

University of California San Diego

Jaekung Go

Samsung Electronics

Sheng $\mathrm{Xu}$

University of California, San Diego https://orcid.org/0000-0002-3120-4992

Joseph Wang ( $\sim$ josephwang@ucsd.edu)

University of California San Diego https://orcid.org/0000-0002-4921-9674

Article

Keywords: 
Posted Date: February 2nd, 2022

DOI: https://doi.org/10.21203/rs.3.rs-1176014/v1

License: (9) This work is licensed under a Creative Commons Attribution 4.0 International License. Read Full License

Version of Record: A version of this preprint was published at Nature Electronics on October 6th, 2022. See the published version at https://doi.org/10.1038/s41928-022-00843-6. 


\section{Abstract}

The lack of compact integration, including fusing of skin-interfaced direct, rapid independent data visualization along with light, safe stretchable batteries, hinders progress towards the creation of fully autonomous comprehensive wearable monitoring platforms. Here we present a highly integrated epidermal sensing platform combining electrochemical sensors with stretchable battery and ultra-low power digital display that instantaneously visualizes the results via 10 individually addressable electrochromic pixels. The all-around stretchable patch can operate independently as a standalone device to directly display the concentration of various electrolytes or metabolites, freeing it from any wired or wireless connection to other equipment. Fabricated via high-throughput printing of customized elastomeric inks, the integrated system presents robust mechanical performance, enduring over 1500 stretching cycles without affecting its sensing and display capabilities. The fast-responding display exhibits stability over 10,000 ON/OFF cycles, and upon coupling with the high-performance stretchable battery, can serve 14,000 sensing sessions in a week-long usage. Merging ultra-low power consumption, independent operation, rapid data display and superior mechanical performance, this fully autonomous multifunctional self-sustainable wearable sensing platform is of high practicality and convenience for diverse practical applications in professional sports, personalized wellness management, and beyond.

\section{Main}

Soft electronics have gathered considerable attention over the past decade as attractive alternatives to their rigid bulky counterparts, for applications in on-body sensing and human-machine interfacing. ${ }^{1-4}$ In particular, many integrated epidermal sensing systems have been developed as "labs-on-the-skin", capable of recording a myriad of mechanical, electrical, physiological, and electrochemical signals, towards applications in healthcare, wellness and fitness. ${ }^{5-8}$ The current development of wearable sensors has evolved from the study of physical and chemical sensors alone towards the integration of sensors with energy management, signal acquisition, and data interfacing electronics. ${ }^{9-14}$ Due to the lack of high-performance wearable batteries, most wearable electronics currently operate with commercial lithium polymer pouches or coin cells, which are rigid, unsafe, and bottlenecks the product design. Avoiding such battery-related design limitations, conformal epidermal sensors were often designed with wired connections or short-range power delivery schemes, which in turn compromise the system autonomy and limit the user's mobility. ${ }^{9,11,15-18}$ Furthermore, such integrated sensors rely on wireless data transmissions, which calls for the need for external devices (e.g., computers, mobile smartphones, customized receivers) for users to obtain the sensing results. ${ }^{9,11,19-21}$ Such lack of direct access to sensing results has led to the inconvenience and impracticality of many existing wearable sensors in their real-life applications. The inclusion of visual data presentation would address these limitations, greatly simplify the workflow, improve the user experience, and offer exciting opportunities for smart flexible electronic systems. Hence, there are major demands and barriers for integrating accurate on-body sensing and real-time display capabilities within a compact flexible wearable monitoring platform. ${ }^{22}$ 
To this end, integrated sensing systems with miniaturized display elements have been developed, offering an attractive route for visualizing the data in real-time for direct readout. ${ }^{13,14,23-26}$ Among the various display technologies, colorimetric assays involve direct chemical reactions with the target analytes, such as glucose or chloride ion, report the results qualitatively via the naked eyes. ${ }^{27}$ Electrochromic materials that change their color or opacity upon applying an electrical potential have also been integrated with sensing systems for data visualization. ${ }^{28-31}$ However, such colorimetric display technologies involve long reaction times and lack spatial and colorimetric resolution associated with the naked eye readout, leading to inaccurate and unclear data presentation. Further analysis is usually required to convert such qualitative colorimetric information to precise numerical data, in connection to smartphones, spectral analyzers, or cameras. ${ }^{24,26,32-34}$ While conventional display technologies have been converted recently to flexible wearable form factors, their high power consumption significantly limits their application in compact low-energy electronic systems. ${ }^{35-37}$ Alternatively, non-emissive displays that consume low power (e.g., liquid crystal and electronic ink displays) and are controlled by microcontrollers can effectively present the processed data; yet, their lack of flexibility and stretchability limits their seamless integration with wearable devices. ${ }^{23,38}$ Thus far, a wearable sensing system integrating power supply, in situ signal acquisition and processing, along with real-time accurate data visualization, into a compatible stretchable form factor, has yet to be developed. Achieving such multifunctionality and self-sustainability will facilitate the creation of fully autonomous next-generation wearable electronics platforms.

Herein, we present an all-in-one powerful epidermal sensing platform with a dedicated electrochromic display (ECD) for rapid visualization of the analytical data along with high-performance battery. The allprinted wearable system is constructed with stretchable batteries featuring a safe $\mathrm{Ag}_{2} \mathrm{O}-\mathrm{Zn}$ chemistry for power supply, stretchable enzymatic and potentiometric electrochemical sensors for sensing various metabolites and electrolytes, along with ten fast responding and highly reversible poly(3,4-ethylene dioxythiophene) polystyrene sulfonate (PEDOT:PSS)-based electrochromic pixels for direct visual data presentation, all controlled by a single low-power microcontroller unit (MCU) chip, reliably attached to the stretchable substrate (Supplementary Movie 1). Designed in a compact epidermal patch form factor, all components were fabricated with high-throughput screen-printing of customized stretchable composite inks on a heat-sealable thermoelastic styrene-ethyl butylene-styrene block copolymer (SEBS) substrate (Fig. 1a and Supplementary Fig. 1). The stretchable silver ink, utilizing chloride/lactic acid treatment, delivery highly stable electrical connection under repeated stretching (Supplementary Fig. 2), and was printed as interconnections between all components within the system. ${ }^{39}$ The system can be easily activated by a press of a switch, that firstly connects the batteries to the MCU, and samples the signal input from the electrochemical sensor via its analog-to-digital converter (ADC). The latter converts the analytical data into digital outputs which instantaneously control the ON and OFF states of 10 individual ECD pixels (Fig. 1b). The attractive performance of the fully integrated multifunctional system was showcased with four types of sensors, including potentiometric sodium ions and $\mathrm{pH}$ sensors and enzymatic amperometric glucose and lactate biosensors, under optimized loads, with the analyte concentrations, displayed instantly on the ECD for directly visual digital readout (Fig. 1C). Such an integrated epidermal patch exhibited excellent durability and mechanical robustness (Fig. 1d-i and ii), 
able to perform over 10,000 sensing sessions over 5 days while enduring thousands of stretching cycles. A rapid room-temperature "solvent welding" process was developed for optimizing the "rigid" and "soft" "rigid" connection, hence securing the connection between the microcontroller and the stretchable substrate along with interconnections during stretching (Fig. 1d-iii and Supplementary Fig. 3). Adapting the use of melanic anhydrite-grafted SEBS (SEBS-MA) can strengthen the bonding of the metal contact pads on the MCU to the substrate, allowing strain up to $300 \%$ strain without detachment (Supplementary Fig. 4). The all-printed multi-functional compact epidermal sensing platform thus integrates the ECD, batteries, and sensors, in a highly flexible, and stretchable form factor. The skin-interfaced platform is entirely autonomous and self-sustainable towards instantaneous sensing and direct visual data presentation and can operate independently from any external equipment. The presented sensing system, with a dedicated stretchable display and battery, is compatible with a myriad of wearable healthcare and wellness applications and paves the way towards a practical "lab-on-the-skin" for comprehensive epidermal monitoring.

\section{All-stretchable PEDOT:PSS electrochromic displays}

Integrating electrochromic displays into skin-interfaced electronic systems provides timely data visualization, such as the level of the target biomarker in the case of on-body sensing platforms. The new skin-interfaced integrated sensing platform features a dedicated and highly responsive low power ECD for such direct visualization of the analytical data. The ECD was chosen for its low power consumption compared to light-emitting display technologies, as it features low self-discharge and requires energy only while refreshing the displaying content. The electrochromic PEDOT:PSS electrode material was selected for its stretchability and compatibility with screen-printing processes. Fabricated via layer-by-layer screen-printing, the ECD was composed of a top PEDOT:PSS panel and 10 separately addressable pixels on the bottom panel, with a highly viscous PSS-based electrolyte to create ionic pathways between two panels while physically separating the opposing electrodes; stretchable and printed silver traces were used to connect the ECD to the MCU and were covered with an insulating elastomer layer to avoid short-circuiting and corrosion (Fig. 2a and Supplementary Fig. 1). The color of the PEDOT:PSS conducting polymer is dependent on its redox state, as described in Equation 1:

$\left(\right.$ PEDOT $^{+}$(PSS) $^{-}$(light blue) $+\mathrm{e}^{-} \leftrightarrow$ PEDOT (dark blue) + PSS $^{-}$

which occurs during the PSS- undoping process upon applying a potential above $1 \mathrm{~V}$ between the two electrodes. Thus, to induce a color change, a positive potential can be applied to the bottom pixels, which results in the color-changing reduction of PEDOT:PSS within the corresponding region on the front panel covered by the block of PSS electrolyte (Fig. $\mathbf{2 b}$ and Supplementary Fig. 5). The printable PEDOT:PSS ink was optimized for stretchability and compatibility to the elastic SEBS substrate, and shows excellent mechanical behavior and electrochemical stability upon repeated $20 \%$ stretching deformation (Fig. $2 \mathrm{c}$ and Supplementary Figure 6). Cyclic voltammetry (CV) of the electrochromic pixel was carried out with 
scan rates of $0.1,0.5,1 \mathrm{~V} / \mathrm{s}$ over the $0 \mathrm{~V}$ to $1.5 \mathrm{~V}$ range (Fig. $2 \mathrm{~d}$ ). The ON/OFF switching ECD was characterized using potential stepping between $0 \mathrm{~V}$ and a set switching voltage while monitoring the current. As shown in Fig. 2e, a switching voltage of $1.5 \mathrm{~V}$ was determined to be optimal as it results in the fastest turn-on and turn-off response below $200 \mathrm{~ms}$. In comparison, the $1 \mathrm{~V}$ switching voltage resulted in a slower turn-on and turn-off speed, whereas switching voltages of $2 \mathrm{~V}$ and $3 \mathrm{~V}$, while giving in a fast turnon rate, led to a slower turn-off speed due to excessive charge accumulation on the electrodes. Such high voltage can also lead to electrolyte breakdown and should be avoided. This behaviour was examined again after 1500 cycles of repeated $20 \%$ uniaxial stretching along with two orthogonal directions. The results, displayed in Fig. 2f and Supplementary Movie 2, demonstrate a slightly reduced turn-on and turnoff current but a negligible change in switching speed, indicating the excellent stretchability of the PEDOT:PSS electrodes. As characterized via electrochemical impedance spectroscopy (Fig. 2g), such reduction in the switching current can be attributed to a slight increase $(<200 \Omega)$ in electrode serial resistance, whereas the charge transfer and diffusion impedance remained mostly constant. The electrochemical stability of the ECD was tested via repeated cycling of the PEDOT:PSS electrodes between on and off (Fig. 2 h-i) over 10000 cycles (Fig. 2 h ii) via potential steps between $0 \mathrm{~V}$ and $1.5 \mathrm{~V}$. The electrical current response of the pixel shows high reproducibility with only $17 \%$ decrease of the peak current after ca. 10000 ON/OFF cycles (Fig. 2h iii - iv and Supplementary Fig. 7). Such high mechanical and electrochemical stabilities ensure the continued and reliable operation of the ECD within the designed lifetime of the system.

\section{Battery performance}

The all-printed fabrication of the flexible $\mathrm{Ag}_{2} \mathrm{O}-\mathrm{Zn}$ battery was designed based on the selection of the substrate and ink formulation that ensures mechanical stretchability, chemical resiliency, operational safety, light weight and comfort, as well as electrochemical stability of the device. SEBS was selected as the binder for both electrodes, separator, as well as substrate, due to its chemical stability in the alkaline electrolyte used in the $\mathrm{Ag}_{2} \mathrm{O}-\mathrm{Zn}$ battery. Furthermore, as thermoelastomer SEBS also allows heat- and vacuum-sealing compatibility, which grants reliable packaging to protect and contain the electrolyte. Polyvinyl alcohol (PVA) hydrogel electrolyte was also formulated to physically contain the electrolyte and avoid leakage. A stacking configuration was designed to minimize the device footprint while reducing the ion diffusion distant between the battery electrodes for minimizing the internal resistance. The batteries, with the customized silver current collector, $\mathrm{Zn}$ anode, $\mathrm{Ag}_{2} \mathrm{O}$ cathode, and $\mathrm{TiO}_{2}$ separator inks, were printed layer-by-layer on the top and bottom panels and assembled via heat and vacuum sealing upon placing the electrolyte hydrogel (Fig. 3a). The redox reaction of the resulting $\mathrm{Ag}_{2} \mathrm{O}-\mathrm{Zn}$ battery relies on the dissolution of zinc ions $\left(\mathrm{Zn}^{2+}\right)$ and silver ions $\left(\mathrm{Ag}^{+}\right)$in the alkaline electrolyte and their supersaturationinduced precipitation, which takes place rapidly while maintaining a stable voltage at $1.56 \mathrm{~V}$ (Fig. $3 \mathrm{~b})$ :

Anode: $\mathrm{Zn}+2 \mathrm{OH}^{-} \leftrightarrow \mathrm{ZnO}+\mathrm{H}_{2} \mathrm{O}+2 e^{-} \mathrm{E}=-1.22 \mathrm{~V}$ versus SHE (2)

Cathode: $\mathrm{Ag}_{2} \mathrm{O}+\mathrm{H}_{2} \mathrm{O}+2 e^{-}=2 \mathrm{Ag}+2 \mathrm{OH}^{-} \mathrm{E}=+0.34 \mathrm{~V}$ versus SHE (3) 
The capacity of such printed stretchable battery can be adjusted by the loading of cathode material, as controlled by the number of layers of printing. As shown in Fig. 3c, batteries with different (1 - 4) layers of cathode printed were prepared and tested at the discharge rate of $1 \mathrm{~mA} \mathrm{~cm}{ }^{-2}$. Such thickness change results in a proportional increase in capacity with the number of layers, reaching as high as $11.5 \mathrm{mAh}$ $\mathrm{cm}^{-2}$ with 4 layers of cathode loading. The power consumption of the MCU was separately characterized at various operation potentials, and the current draw at the voltage of $1.55 \mathrm{~V}$ was determined to be at ca. $1 \mathrm{~mA}$ (Supplementary Fig. 8). The operation of the system was tested with $1 \mathrm{~s}$ of discharge at $1 \mathrm{~mA}$ discharge every $30 \mathrm{~s}$, which simulates the repeated sensing and display sessions upon pressing the switch mechanism. As shown in Fig. 3d, the battery (with 2 layers of cathode) is able to deliver a stable voltage with a constant small ohmic drop throughout the continued usage of the device, indicating a constant cell impedance over its entire range of state of charge. Using this simulated discharge profile where the sensor is used twice every minute - the system can provide energy for over 14000 sensing sessions, corresponding to a service time of over ca. 120 hours. The mechanical stability of the battery under repeated uniaxial stretching was evaluated at $1 \mathrm{~mA}$ discharge for 1500 cycles of $20 \%$ uniaxial stretching (Fig. 3e, Supplementary Fig. 9, and Supplementary Movie 1). As shown in Fig. 3f, the increase in ohmic drop due to the battery stretching was insignificant to the voltage delivered during the continuous $1 \mathrm{~mA}$ discharge, thus confirming its mechanical robustness as a reliable power source for the stretchable epidermal sensing platform. Moreover, the shelf-life of the battery was tested over 1000 hours, displaying a negligible change in voltage and internal resistance at $<40 \Omega$ (Supplementary Fig. 10), reflecting the high chemical stability of the electrodes, electrolyte, and the packaging materials.

\section{Stretchable display system with potentiometric sensors}

Two types of potentiometric sensors, for monitoring $\mathrm{pH}$ and sodium, were employed for demonstrating the applicability of the all-in-one sensing device. Both sensors rely on measuring the potential difference between the modified working electrode and the silver/silver chloride $(\mathrm{Ag} / \mathrm{AgCl})$ reference electrode when in contact with the sample solution (Fig. 4a). Such potentiometric sensing applies to a wide range of clinically or environmentally important electrolytes. By printing the stretchable silver ink and carbon ink on the SEBS substrate, the two-electrode sensor shows satisfactory resiliency to $20 \%$ stretching (Fig. $4 \mathrm{~b}$ iii). The electrode-electrolyte interface of sodium-ion-selective membrane-modified sodium sensor results in a sodium concentration gradient (between the membrane and the solution), leading to a potential signal that depends logarithmically on the sodium concentration (Fig. 4c i). Fig. 4c ii depicts the calibration of the fabricated sodium sensor, demonstrating a slope of $62.4 \mathrm{mV}$ per decade of sodium concentration, with a high correlation coefficient $\left(R^{2}=0.9996\right)$, over the $0.1-100 \mathrm{mM}$ range. The high selectivity of the sodium sensor is demonstrated from the negligible change in the sensor potential response in the presence of potassium and different pH (Supplementary Fig. 11). As shown in Fig. 4c iii, the potential response of the sensor in alternating $0.1 \mathrm{mM}$ and $10 \mathrm{mM}$ sodium solutions is highly 
reversible and exhibits minimal changes after 500, 1000, and 1500 stretching cycles, reflecting the excellent stretchability of the sodium sensor.

The $\mathrm{pH}$ sensor is fabricated by the electropolymerization of polyaniline (PANI) onto the working carbon electrode. The operation of the resulting $\mathrm{pH}$ sensor is based on the protonation and de-protonation of nitrogen atoms in the polymer chains of PANI (Fig. $4 \mathrm{~d} \mathrm{i}$ ). The sensitivity of the fabricated pH sensor is evaluated by measuring the potential response at $\mathrm{pH}$ values in the range of 3 - 8 (Fig. $4 \mathrm{~d} \mathrm{i}$ ). The sensors display a linear response of $62.62 \mathrm{mV} / \mathrm{pH}$ with a high correlation coefficient $\left(R^{2}=0.9995\right)$ across the entire $\mathrm{pH}$ range (Fig. $4 \mathrm{~d}$ ii). As illustrated in Fig. $4 \mathrm{~d}$ iii, the modified pH sensor displays excellent stretchability, as evidenced by the highly stable potential signals measured at $\mathrm{pH} 4$ and $\mathrm{pH} 7$, with negligible changes after 500,1000, and 1500 times of stretching. In addition, the pH sensor demonstrates good selectivity in the presence of $\mathrm{Na}^{+}$and $\mathrm{K}^{+}$(Supplementary Fig. 12). The operating voltage obtained from sodium and $\mathrm{pH}$ sensors is converted into logic outputs, programming the $\mathrm{MCU}$ and correlating the obtained voltage values to the display content (Fig. 4e). By integrating the $\mathrm{pH}$ sensor with the ECD, we thus fabricated an all-in-one epidermal patch for instant pH sensing and display (Fig. $4 \mathrm{f} \mathrm{i-ii).}$

\section{Stretchable display system with enzymatic sensors}

Two enzymatic sensors for glucose and lactate were selected to demonstrate the applicability of the integrated ECD patch in a real-life scenario for epidermal sensing of both metabolites. Both enzymatic sensors commonly rely on amperometric measurements, where the electrical current at a set potential can be linearly correlated to the metabolite concentration within a certain range. To enable rapid and lowpower consumption sensing while obviating the need for potentiostats and amplifiers and removing them from the circuits, a self-powered sensing mechanism that converts the amperometric signal to a voltage signal was implemented under an optimized load. The sensor electrodes are composed of a printed carbon working electrode along with a silver oxide $\left(\mathrm{Ag}_{2} \mathrm{O}\right)$ counter electrode, where the carbon electrodes were thereafter functionalized with the corresponding enzymes for their target analytes (Fig. 5a). Fig. 5b displays the lengthwise stretching of the enzymatic sensor fabricated using the customized stretchable inks. The lactate sensor operates based on the selective naphthoquinone (NQ)-mediated oxidation of lactate on the working electrode by the lactate oxidase (LOx) enzyme, immobilized on carbon nanotubes. The working electrode is coupled with the $\mathrm{Ag}_{2} \mathrm{O}$ counter electrode that undergoes a high reaction-rate reduction of $\mathrm{Ag}_{2} \mathrm{O}$ to $\mathrm{Ag}$, independent of the analyte concentration. Upon applying a load, a continuous current flows between the enzyme electrode and the $\mathrm{Ag}_{2} \mathrm{O}$ electrode, which is dominated by the concentration-limited electrocatalytic reaction on the LOx electrode (Fig. $5 \mathrm{c}-\mathrm{i})$. The optimization of the load ensures a maximized signal resolution over a desired concentration region. To this end, linear sweep voltammetry (LSV) was performed at two different lactate concentrations ( $0 \mathrm{mM}$ and $25 \mathrm{mM}$ ), and the potential was plotted against the load, as illustrated in Fig. $5 \mathrm{c}$-ii. As shown, a load of $75 \mathrm{k} \Omega$ was selected, where the potential difference between $0 \mathrm{mM}$ and $25 \mathrm{mM}$ lactate was at the maximum. Subsequently, the in-vitro voltage response of the lactate sensor at different concentrations was measured under the $75 \mathrm{k} \Omega$ 
load and fitted with an exponential model (Fig. $5 \mathrm{c} \mathrm{iii).}{ }^{40}$ To further illustrate the importance of optimizing the load to the range and resolution of the lactate sensor, the sensor was also tested under different loads of $10 \mathrm{k} \Omega$ and $500 \mathrm{k} \Omega$ (Supplementary Fig. 13). This test showed a minimal potential change above the lactate concentration of $10 \mathrm{mM}$ under the $500 \mathrm{k} \Omega$, and poor voltage resolution across $0-30 \mathrm{mM}$ lactate concentrations under the $10 \mathrm{k} \Omega$ load. Fig. $5 \mathrm{c}$-iv examines the stretchability of the lactate sensor, demonstrating highly stable and reversible voltage signal after 1500 cycles of lengthwise uniaxial $20 \%$ stretching. Additional characterization shows that the lactate sensor exhibits effective discrimination against common sweat constituents, including urea, ascorbate, acetaminophen, and glucose (Supplementary Fig. 14), as well as high electrochemical stability, operating continuously over 9 hours (Supplementary Fig. 15), and compatibility for epidermal lactate sensing using artificial sweat samples. Considering the potentially changing $\mathrm{pH}$ of human sweat, the fabricated lactate sensor was tested in different artificial sweats with variable pH of 5.5, 6.5, and 7.4 (Supplementary Fig. 16). No significant differences in potentiometric response were observed among the tested samples, demonstrating the reliability and practicality of the sensor.

Using a similar 2-electrode construction, the NQ-mediated glucose oxidase (GOx) was used to obtain a highly selective glucose-sensing working electrode in connection to an $\mathrm{Ag}_{2} \mathrm{O}$ counter electrode (Fig. $5 \mathrm{~d} \mathrm{i}$ ). The load was optimized similarly via LSV at $75 \mathrm{k} \Omega$ and using $0 \mathrm{mM}$ and $20 \mathrm{mM}$ glucose solutions (Fig. 5d ii). The well-defined potential response of the resulting glucose sensor over the 0-10 mM range is presented in Fig. 5d iii, while its high selectivity against common sweat constituents, including uric acid, ascorbic acid, acetaminophen and lactate, is displayed in Supplementary Fig. 17. The stretchability of the sensor was assessed via stretching the electrode while recording its potential response to 2.5 and $10 \mathrm{mM}$ glucose solutions. As illustrated in Figure $5 \mathrm{~d}$ iv, the glucose response remained highly stable after 1500 cycles of lengthwise uniaxial $20 \%$ stretching. Similar to the lactate sensor, the glucose sensor was tested in artificial sweat in variable pHs, demonstrating a stable voltage signal regardless of the environment, and confirming its practicality under real-life operating conditions (Supplementary Fig. 18). It is worth noting that such current-to-voltage signal conversion can be modified to accommodate the lower glucose concentration in human sweat. This is accomplished by adjusting the load to a higher value which enhances the signal resolution in lower concentration in exchange to a larger range. To this end, another optimized load at $250 \mathrm{k} \Omega$ is applied, leading to a greatly enhanced voltage difference for glucose concentrations over the $0-5 \mathrm{mM}$ range (Supplementary Fig. 19).

Based on the results obtained from glucose and lactate sensors, the MCU can be programmed to convert the voltage response of the sensors to the 10-pixel digital display (Fig. 5e). The on-body application of the epidermal device was demonstrated by integrating the all-in-one lactate sensor system. As shown in Fig. $5 f$, the epidermal patch perfectly matches the skin curvature of the subject's forearm. After sweat is induced from the loaded exercise, the subject can mount the integrated system on the forearm for demonstrating its application in real conditions. The sensor was thus able to instantly display the lactate concentration on the wearer's skin without needing any external electronic, allowing the user to directly obtain the sensing results. The observed lactate level changed from the initial $2.5 \mathrm{mM}$ at the beginning of 
the perspiration to $7.5 \mathrm{mM}$ after $5 \mathrm{~min}$, reflecting changes in the metabolic activity of the sweat gland. (Fig. $5 f$ ii-iii).

\section{Conclusions}

In summary, we have presented an all-printed multi-functional autonomous epidermal monitoring system integrating the electrochemical sensors, ECD, and batteries, all in a highly compact, flexible and stretchable form factor. The new integrated sensing platform features a dedicated and highly responsive low power ECD for instantaneous visual data presentation, along with a high-performance safe printed $\mathrm{Ag}_{2} \mathrm{O}-\mathrm{Zn}$ battery that can power over 14,000 discrete sensing sessions while enduring thousands stretching cycles, for wearable sweat-monitoring applications. Through the use of stress-enduring and chemically stable SEBS elastomer as the substrate and binder, highly stretchable devices have been fabricated via low-cost, high-throughput layer-by-layer stencil printing of formulated composite inks into a mechanically resilient epidermal platform. Utilizing PEDOT:PSS electrode material, the ECD exhibited high electrochemical and mechanical stability over 10,000 of ON/OFF cycling and 1,500 stretching cycles, endowing users with the ability to obtain accurate sensing data rapidly, directly, and independently, without needing external devices. A wide range of sensors, including potentiometric $\mathrm{pH}$ and sodium electrolyte sensing devices, and enzymatic glucose and lactate metabolic biosensing, were shown compatible with the integrated sensing platform, demonstrating the broad scope of the presented ECDbased data visualization. Our approach, combining high performance ECD and battery technologies, all in a highly compact and stretchable form factor that is compatible to commercially available MCUs, thus offers a practical solution to direct and real-time data visualization. Such development of mechanically resilient skin-worn multifunctional monitoring-display platform is extremely useful for simultaneously sensing and directly visualizing the analytical information towards the creation of fully autonomous selfsustainable next-generation wearable monitoring platforms. Flexible microgrids are currently being designed for realizing such fully sustainable operation of autonomous wearable electronics. ${ }^{13,41} \mathrm{We}$ expect the coupling of stretchable ECDs and batteries to be increasingly explored towards improving user experience in wearable electronics platforms for personal wellness management, healthcare monitoring, professional sports, and beyond.

\section{Methods}

\section{Chemicals}

Graphite, toluene, acetone, ethanol, hydrochloric acid ( $\mathrm{HCl})$, 1,4-naphthoquinone (NQ), chitosan, glutaraldehyde, acetic acid, Nafion, lactatic acid, D-(+)-glucose, glucose oxidase (GOx), Ag flake, $\mathrm{Ag}_{2} \mathrm{O}$ powder, zinc $(\mathrm{Zn})$, zinc oxide $(\mathrm{ZnO})$, bismuth trioxide $\left(\mathrm{Bi}_{2} \mathrm{O}_{3}\right)$, titanium dioxide $\left(\mathrm{TiO}_{2}\right)$, sodium ionophore $\mathrm{X}$, sodium tetrakis[3,5-bis(trifluoromethyl)phenyl]borate (Na-TFPB), bis(2-ethylhexyl) sebacate (DOS), tetrahydrofuran (THF), polyvinyl butyral (PVB), poly(vinyl chloride) (PVC), sodium chloride ( $\mathrm{NaCl}$ ), polystyrene-block-poly(ethylene-ran-butylene)-block-polystyrene-graft-maleic anhydride (SEBS-MA), 
methanol, iron (III) chloride $\left(\mathrm{FeCl}_{3}\right)$, aniline, sodium phosphate anhydrous, citric acid, sodium polystyrene sulfonate (PSSNa), glycerol, D-sorbital, acrylamide, $\mathrm{N}, \mathrm{N}$ '-methylenebisacrylamide, potassium peroxydisulfate, sodium dodecylbenzene sulfonate (DBSS) were all purchased from Sigma Aldrich. The polyurethane (PU) (Tecoflex EG-80A) was obtained from Lubrizol. Styrene-ethylene-butylene-styrene (SEBS G1645) triblock copolymer was obtained from Kraton. MWCNT-COOH was purchased from Cheap Tubes inc. The screen printable PEDOT:PSS paste was purchased from Sun Chemical. The lactate oxidase (LOx) was purchased from Toyobo. The Capstone ${ }^{\mathrm{TM}}$ fluorosurfactant FS- 65 was purchased from DuPont. The GBR6005 was obtained from Daikin. All electrochemical measurements were performed on Autolab PGSTAT204 potentiostat/galvanostat from Metrohm.

\section{Fabrication of the electrochromic display}

The substrate for the ECD was composed of styrene ethylene butylene styrene (SEBS) dissolved in toluene (40 wt\%) and was fabricated by doctor blade casting (1000 $\mu \mathrm{m}$ thick) the SEBS then followed by curing in the oven at $80^{\circ} \mathrm{C}$ for 1 hour.

The ECD was fabricated using layer-by-layer screen-printing with customized four kinds of inks: the electrochromic poly(3,4-ethylenedioxythiophene) polystyrene sulfonate (PEDOT:PSS) ink, the silver ink for interconnection, the opaque insulator ink composed of $\mathrm{SEBS}$ and $\mathrm{TiO}_{2}$, and the sodium polystyrene sulfonate-based electrolyte ink. The PEDOT:PSS ink was prepared using $1 \mathrm{~g}$ of PEDOT:PSS paste, $0.2 \mathrm{~mL}$ of toluene, $0.15 \mathrm{~mL}$ DBSS ( $75 \mathrm{mg} \mathrm{ml}^{-1}$ in DI water), and $0.0135 \mathrm{~mL}$ of CapstoneTM fluorosurfactant FS65. The silver ink was composed of silver flake, SEBS (40 wt\% in toluene) and toluene in 4:2:1 weight ratio. The opaque insulator ink was composed of $\mathrm{TiO}_{2}$, SEBS (40 wt\% in toluene) in 1: 10 weight ratio. The PSSNa electrolyte ink was formulated by mixing PSSNa, D-sorbitol, glycerol, $\mathrm{TiO}_{2}$, and polyacrylamide (PAM) precursor solution in 4:1:1:0.8:2 weight ratio. The PAM solution was formulated by mixing acrylamide, DI water, potassium peroxydisulfate, and $\mathrm{N}, \mathrm{N}$ '-methylenebisacrylamide in 2:10:0.05:0.02 ratio. All inks are mixed in the planetary mixer at $1800 \mathrm{rpm}$ for $10 \mathrm{~min}$ or until homogenous.

The ECD panel was composed of the color-changing top panel and the bottom panel to control the regional color change. The PEDOT:PSS ink was printed first onto the SEBS substrate and cured in the oven at $100^{\circ} \mathrm{C}$ for $2 \mathrm{~h}$. Then, the silver interconnection and the opaque insulator layers were printed, with each layer cured at $80^{\circ} \mathrm{C}$ for $5 \mathrm{~min}$. Before assembly, the electrolyte was printed onto the bottom panel and briefly heated in the oven for $15 \mathrm{~s}$ at $80^{\circ} \mathrm{C}$ to cross-link the PAM in the electrolyte.

\section{Fabrication of the stretchable battery}

The printing of the battery relied on four inks: $\mathrm{Ag}$ ink as current collector, $\mathrm{Zn}$ ink as anode, $\mathrm{Ag}_{2} \mathrm{O}$ ink as cathode and separator ink. The $\mathrm{Zn}$ ink is prepared using $\mathrm{Zn}, \mathrm{ZnO}, \mathrm{Bi}_{2} \mathrm{O}_{3}$ and $\mathrm{GBR}$ binder $(25 \mathrm{wt} \%$ in acetone) in 9:0.5:0.5:0.267 weight ratio. The $\mathrm{Ag}_{2} \mathrm{O}$ ink was prepared using $\mathrm{Ag}_{2} \mathrm{O}$, super $\mathrm{P}$ carbon black and GBR binder (33 wt\% in acetone) in 1.9:0.1:2.66 weight ratio. The separator ink was composed of 
$\mathrm{TiO}_{2}$, TritonX-114, SEBS (40 wt\% in toluene) and toluene in 3:0.1:1.5:1.5 weight ratio. All inks were mixed in the planetary mixer at $2500 \mathrm{rpm}$ for $10 \mathrm{~min}$ or until homogenous.

The stretchable battery was composed of two pairs of $\mathrm{Zn}-\mathrm{Ag}_{2} \mathrm{O}$ battery printed on the bottom and top panels, separately. The layer-by-layer printing steps of the battery were followed by using Ag ink, Zn anode or $\mathrm{Ag}_{2} \mathrm{O}$ cathode ink and separator ink, with each layer cured at $80^{\circ} \mathrm{C}$ for 5 min (Supplementary Fig. 1). Before assembly, a PVA electrolyte gel was placed between the anode and cathode, and a concentric circle switch was placed between the Ag interconnection of two panels. After aligning and combining two panels, the battery can work and power the MCU effectively by pressing the switch.

\section{Fabrication of the potentiometric sensors}

The sodium sensors and $\mathrm{pH}$ sensors were fabricated by using flexible silver and carbon inks. The formulation of the Ag ink is described above. The carbon ink was prepared using graphite, super-P carbon black, SEBS (40 wt\% in toluene), and toluene in a 6:1:8.4:2.1 weight ratio. Both inks were mixed in a planetary mixer at $1800 \mathrm{rpm}$ for $10 \mathrm{~min}$ or until homogenous.

The silver ink and the carbon ink were printed onto the top panel SEBS substrate layer-by-layer and were covered using SEBS resin to define the electrode area, exposing $2 \mathrm{~mm}^{2}$ of carbon electrode as the

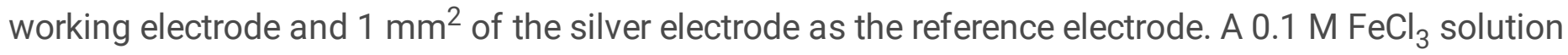
was drop-cast onto the silver electrode to chlorinate the surface and form $\mathrm{AgCl}$.

\section{Fabrication of the sodium sensor}

The sodium sensor was based on screen printed electrodes modified via drop-casting. A cocktail composed of PVB $\left(78.1 \mathrm{mg} \mathrm{ml}^{-1}\right)$ and sodium chloride $\left(50 \mathrm{mg} \mathrm{ml}^{-1}\right)$ dissolved in methanol was drop-cast onto the chlorinated reference surface $\left(1.5 \mu \mathrm{mm}^{-2}\right)$. A PU resin (1 $\mathrm{g}$ in $\left.20 \mathrm{~g} \mathrm{THF}\right)$ was then drop-cast onto the dried cocktail layer $\left(2 \mu \mathrm{mm}^{-2}\right)$ to prevent leaching. A cocktail for the sodium ion-selective electrode was formulated by dissolving $1 \mathrm{mg}$ of sodium ionophore $\mathrm{X}, 0.77 \mathrm{mg} \mathrm{Na-TFPB}$ ion exchanger, 33 mg PVC, and $66 \mathrm{mg}$ DOS in $660 \mathrm{~mL}$ nitrogen-purged THF. The resulting cocktail was subsequently dropcast onto the carbon electrode $\left(2 \mu \mathrm{mm}^{-2}\right)$.

\section{Fabrication of the $\mathrm{pH}$ sensor}

Following the screen-printing fabrication protocol, the working and reference electrodes were created. The $\mathrm{pH}$ sensor was prepared by electropolymerization of aniline onto the working carbon layer. The carbon electrode was first electrochemically cleaned via 10 cyclic voltametric (CV) scans in $0.5 \mathrm{M} \mathrm{HCl}(40 \mu \mathrm{L})$ from $0.3 \mathrm{~V}$ to $1.1 \mathrm{~V}$ vs. $\mathrm{Ag} / \mathrm{AgCl}$ at a scan rate of $0.1 \mathrm{~V} \mathrm{~s}^{-1}$. Subsequently, polyaniline (PANi) electropolymerization was performed with a solution containing $0.1 \mathrm{M}$ aniline in $1 \mathrm{M} \mathrm{HCl}$ by cyclic voltammetry (CV) from $-0.2 \mathrm{~V}$ to $1.0 \mathrm{~V}\left(\mathrm{vs}\right.$. $\mathrm{Ag} / \mathrm{AgCl}$ ) at $0.05 \mathrm{~V} \mathrm{~s}^{-1}$ to accumulative gain around $100 \mathrm{mC}$ charge on the carbon electrode. Subsequently, the electrode was washed with DI water and was allowed to air-dry. 


\section{Fabrication of the enzymatic sensors}

The glucose sensor and lactate sensor were fabricated by using flexible silver ink, carbon ink and $\mathrm{Ag}_{2} \mathrm{O}$ ink as cathode. The $\mathrm{Ag}_{2} \mathrm{O}$ ink is prepared by mixing $\mathrm{Ag}_{2} \mathrm{O}$, super $\mathrm{P}$ carbon black and GBR binder (21 wt\% in acetone) in a 1.9:0.1:3.166 weight ratio. The $\mathrm{Ag}_{2} \mathrm{O}$ is mixed in a planetary mixer at $2500 \mathrm{rpm}$ for $10 \mathrm{~min}$ or until homogenous.

The silver ink and the carbon ink were printed onto SEBS substrate layer-by-layer followed by printing the $\mathrm{Ag}_{2} \mathrm{O}$ ink onto one of the carbon electrodes to obtain the cathode of both sensors. Finally, the electrodes were covered using SEBS resin to define the electrode area, exposing $2 \mathrm{~mm}^{2}$ of carbon electrode as the anode and $2 \mathrm{~mm}^{2}$ of the $\mathrm{Ag}_{2} \mathrm{O}$ electrode as the cathode.

\section{Modification of the glucose sensor}

The glucose sensor was fabricated by drop casting 0.2 M NQ solution dissolved in acetone: ethanol (9:1) mixture containing $2 \mathrm{mg} / \mathrm{mL}$ CNT-COOH onto carbon electrode $\left(1.5 \mu \mathrm{L} \mathrm{mm}{ }^{-2}\right)$. Then $40 \mathrm{mg} / \mathrm{mL} \mathrm{GOx}$ solution dissolved in PBS containing $10 \mathrm{mg} / \mathrm{mL}$ BSA was drop casting after the first lay drying $(1.5 \mu \mathrm{L}$ $\mathrm{mm}^{-2}$ ). Finally, $1.5 \mu \mathrm{mm}^{-2}$ chitosan layer ( $1 \mathrm{wt} \%$ in $0.1 \mathrm{M}$ acetic acid) and a $0.75 \mu \mathrm{Lm}^{-2}$ glutaraldehyde layer ( $1 \%$ in water) were drop cast on the top for improved immobilization. $A 75 \mathrm{k} \Omega$ resistor was solvent-welded between the two electrodes as the discharging load.

\section{Modification of the lactate sensor}

The lactate sensor was fabricated similarly with glucose sensor, which drop cast $0.2 \mathrm{M}$ NQ solution containing $2 \mathrm{mg} / \mathrm{mL}$ CNT-COOH $\left(1.5 \mu \mathrm{Lm}^{-2}\right)$, followed by $40 \mathrm{mg} / \mathrm{mL}$ LOx solution dissolved in PBS containing $10 \mathrm{mg} / \mathrm{mL} \mathrm{BSA}\left(1.5 \mu \mathrm{L} \mathrm{mm}^{-2}\right)$, as well as $1.5 \mu \mathrm{mm}^{-2}$ chitosan ( $1 \mathrm{wt} \%$ in $0.1 \mathrm{M}$ acetic acid) and $0.75 \mu \mathrm{L} \mathrm{mm}{ }^{-2}$ glutaraldehyde ( $0.5 \%$ in water) layer by layer after each layer drying. Finally, $0.75 \mu \mathrm{L}$ $\mathrm{mm}^{-2} \mathrm{PVC}$ layer (3\% in tetrahydrofuran) was drop cast on the top for enzyme immobilization.

\section{Electrical circuit design}

The control circuit was designed to digitalize the sensor output and control the ECD ( Supplementary Fig. S20 ). A MCU (ATtiny 441, Microchip Technology, USA) with a 10-bit built-in analog-to-digital converter was used. The sensor voltage was firstly digitalized and then displayed by the 10-bit ECD. The sensor readout was mapped to the display bits per their corresponding sensor calibration curve, and the ECD would address individual pixels corresponding to the sensor voltage.

\section{Assembly of the self-powered sensing system}

The microcontroller (MCU) chip was placed onto the bottom panel after the procedure of screen printing above by the "solvent welding" process to connect with Ag layer precisely. The connected MCU was sealed by $0.1 \mathrm{~mL}$ SEBS ( $40 \mathrm{wt} \%$ in toluene) and cured in the oven at $80^{\circ} \mathrm{C}$ for $30 \mathrm{~min}$ after drying in room temperature. Subsequently, the electrolyte is printed onto the bottom panel and briefly cross-link the PAM 
in the electrolyte. Two PVA gels were placed onto the $\mathrm{Zn}$ anode and $\mathrm{Ag}_{2} \mathrm{O}$ cathode of the bottom panel as electrolyte of the battery. The top panel was then aligned and covered onto the bottom panel. Lastly, the assembled device was heat-sealed on all four sides to finish the device assembly.

\section{Data Availability}

The data that support the findings of this study are available from the corresponding author upon reasonable request.

\section{Code Availability}

The code for programming the MCU are available from the corresponding author upon reasonable request.

\section{Declarations}

\section{Acknowledgement}

L.Y. and K.N.K. recognize funding support from Samsung Display. K.N.K recognize funding from National Research Foundation of Korea (NRF-2018R1A6A3A03011252). We would like to thank Kraton Corporation for providing all the SEBS samples.

\section{Author Information}

\section{Affiliations}

Department of Nanoengineering, University of California San Diego, La Jolla, CA, USA

Lu Yin, Mengzhu Cao, Kyeong Nam Kim, Muyang Lin, Juliane R. Sempionatto, Jong-Min Moon, Jialu Yu, Alexander Trifonov, Fangyu Zhang, Hongjie Hu, Sheng Xu \& Joseph Wang

Samsung Display Co., Ltd., Gyeonggi-do, South Korea

Jaekung Go

\section{Author contributions}

L.Y., M.C., and K.N.K. contributed equally to this work. L.Y., K.N.K., and J.W., conceived the idea for this word. L.Y., M.C., K.N.K., A.T., and J.W., designed the experiments, and wrote the manuscript. L.Y., M.C., J.R.S., J.-M.M, A.T., F.Z., and H.H. conducted experiments. L.Y., M.C., and J.Y. fabricated samples. M.L. 
designed and programmed the electronics. A.T., J.G., S.X. and J.W. provided suggestions to experiment designs. L.Y., M.C., K.Y.K., J.R.S., and J.W. designed the figures and revised the manuscript.

\section{Competing interest}

The authors declare no conflict of interests.

\section{References}

1. Wang, C., Wang, C., Huang, Z. \& Xu, S. Materials and Structures toward Soft Electronics. Advanced Materials 30, 1801368 (2018).

2. Ray, T. R. et al. Bio-Integrated Wearable Systems: A Comprehensive Review. Chem. Rev. 119, 54615533 (2019).

3. Kang, J., Tok, J. B.-H. \& Bao, Z. Self-healing soft electronics. Nature Electronics 2, 144-150 (2019).

4. Shih, B. et al. Electronic skins and machine learning for intelligent soft robots. Science Robotics 5, eaaz9239 (2020).

5. Liu, Y., Pharr, M. \& Salvatore, G. A. Lab-on-Skin: A Review of Flexible and Stretchable Electronics for Wearable Health Monitoring. ACS Nano 11, 9614-9635 (2017).

6. Kim, J., Campbell, A. S., de Ávila, B. E.-F. \& Wang, J. Wearable biosensors for healthcare monitoring. Nat. Biotechnol. 37, 389-406 (2019).

7. Yang, Y. \& Gao, W. Wearable and flexible electronics for continuous molecular monitoring. Chemical Society Reviews 48, 1465-1491 (2019).

8. Gao, W., Ota, H., Kiriya, D., Takei, K. \& Javey, A. Flexible Electronics toward Wearable Sensing. Acc. Chem. Res. 52, 523-533 (2019).

9. Gao, W. et al. Fully integrated wearable sensor arrays for multiplexed in situ perspiration analysis. Nature 529, 509-514 (2016).

10. Emaminejad, S. et al. Autonomous sweat extraction and analysis applied to cystic fibrosis and glucose monitoring using a fully integrated wearable platform. Proceedings of the National Academy of Sciences of the United States of America 114, 4625-4630 (2017).

11. Chung, H. U. et al. Binodal, wireless epidermal electronic systems with in-sensor analytics for neonatal intensive care. Science 363, eaau0780 (2019).

12. Manjakkal, L., Yin, L., Nathan, A., Wang, J. \& Dahiya, R. Energy Autonomous Sweat-Based Wearable Systems. Advanced Materials 33, 2100899 (2021).

13. Yin, L. et al. A self-sustainable wearable multi-modular E-textile bioenergy microgrid system. Nature Communications 12, 1542 (2021).

14. Yin, L. et al. A passive perspiration biofuel cell: High energy return on investment. Joule 5, 18881904 (2021). 
15. Kim, D.-H. et al. Epidermal Electronics. Science 333, 838-843 (2011).

16. Kim, J. et al. Battery-free, stretchable optoelectronic systems for wireless optical characterization of the skin. Science Advances 2, e1600418 (2016).

17. Yin, L. et al. High Performance Printed AgO-Zn Rechargeable Battery for Flexible Electronics. Joule 5, 228-248 (2021).

18. Occupational Safety and Health Administration. Preventing Fire and/or Explosion Injury from Small and Wearable Lithium Battery Powered Devices. (2016).

19. Kim, J. et al. Noninvasive Alcohol Monitoring Using a Wearable Tattoo-Based lontophoreticBiosensing System. ACS Sens. 1, 1011-1019 (2016).

20. Song, Y. et al. Wireless battery-free wearable sweat sensor powered by human motion. Science Advances 6, eaay9842 (2020).

21. Kim, H.-J. et al. Review of Near-Field Wireless Power and Communication for Biomedical Applications. IEEE Access 5, 21264-21285 (2017).

22. Kim, E. H. et al. Organic light emitting board for dynamic interactive display. Nat Commun 8, 14964 (2017).

23. Zhao, J. et al. A Fully Integrated and Self-Powered Smartwatch for Continuous Sweat Glucose Monitoring. ACS Sens. 4, 1925-1933 (2019).

24. Bandodkar, A. J. et al. Battery-free, skin-interfaced microfluidic/electronic systems for simultaneous electrochemical, colorimetric, and volumetric analysis of sweat. Science Advances 5, eaav3294 (2019).

25. Koh, A. et al. A soft, wearable microfluidic device for the capture, storage, and colorimetric sensing of sweat. Science translational medicine 8, 366ra165 (2016).

26. Choi, J. et al. Soft, Skin-Integrated Multifunctional Microfluidic Systems for Accurate Colorimetric Analysis of Sweat Biomarkers and Temperature. ACS Sens. 4, 379-388 (2019).

27. Ghaffari, R. et al. Soft Wearable Systems for Colorimetric and Electrochemical Analysis of Biofluids. Advanced Functional Materials 30, 1907269 (2020).

28. Aller-Pellitero, M. et al. Fully-printed and silicon free self-powered electrochromic biosensors: Towards naked eye quantification. Sensors and Actuators B: Chemical 306, 127535 (2020).

29. Sun, X. et al. A naked-eye readout self-powered electrochemical biosensor toward indoor formaldehyde: On-site detection and exposure risk warning. Biosensors and Bioelectronics 177, 112975 (2021).

30. Santiago-Malagón, S. et al. A self-powered skin-patch electrochromic biosensor. Biosensors and Bioelectronics 175, 112879 (2021).

31. Farahmand Nejad, M. A. et al. Electrochromism: An emerging and promising approach in (bio)sensing technology. Materials Today (2021) doi:10.1016/j.mattod.2021.06.015.

32. Li, Z. \& Suslick, K. S. Portable Optoelectronic Nose for Monitoring Meat Freshness. ACS Sens. 1, $1330-1335$ (2016). 
33. Gao, L. et al. Epidermal photonic devices for quantitative imaging of temperature and thermal transport characteristics of the skin. Nat Commun 5, 4938 (2014).

34. Araki, H. et al. Materials and Device Designs for an Epidermal UV Colorimetric Dosimeter with Near Field Communication Capabilities. Advanced Functional Materials 27, 1604465 (2017).

35. Kim, J. et al. Ultrathin Quantum Dot Display Integrated with Wearable Electronics. Advanced Materials 29, 1700217 (2017).

36. Shi, X. et al. Large-area display textiles integrated with functional systems. Nature 591, 240-245 (2021).

37. Miyamoto, A. et al. Inflammation-free, gas-permeable, lightweight, stretchable on-skin electronics with nanomeshes. Nature Nanotech 12, 907-913 (2017).

38. Pu, X. et al. Wearable Power-Textiles by Integrating Fabric Triboelectric Nanogenerators and FiberShaped Dye-Sensitized Solar Cells. Advanced Energy Materials 6, 1601048 (2016).

39. Lv, J. et al. Printable elastomeric electrodes with sweat-enhanced conductivity for wearables. Science Advances 7, eabg8433.

40. Jin, X. et al. Modeling, design guidelines, and detection limits of self-powered enzymatic biofuel cellbased sensors. Biosensors and Bioelectronics 168, 112493 (2020).

41. Yin, L., Kim, K. N., Trifonov, A., Podhajny, T. \& Wang, J. Designing wearable microgrids: towards autonomous sustainable on-body energy management. Energy Environ. Sci. (2021) doi:10.1039/D1EE03113A.

\section{Figures}


a
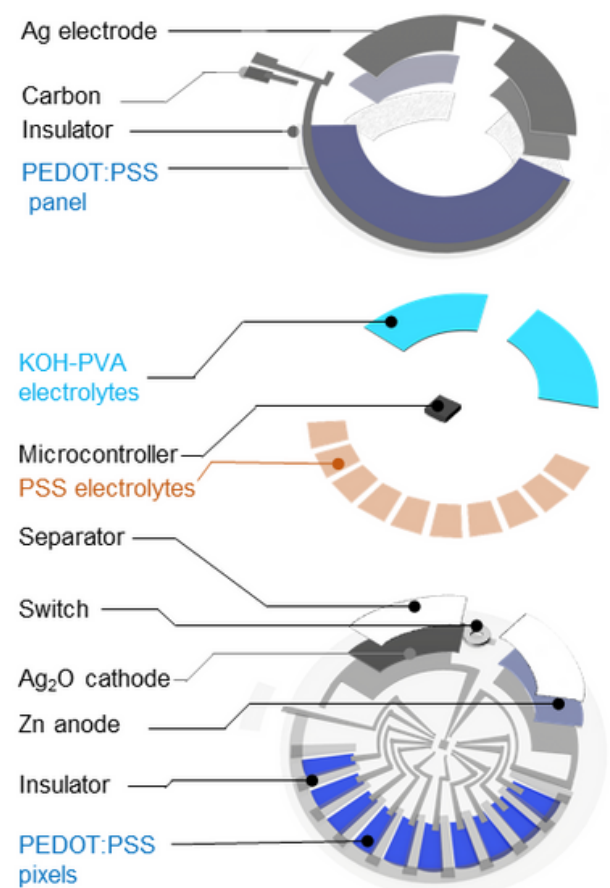

d

i

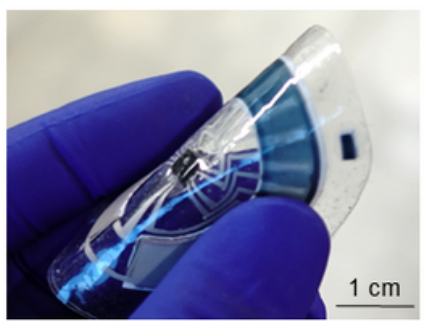

b

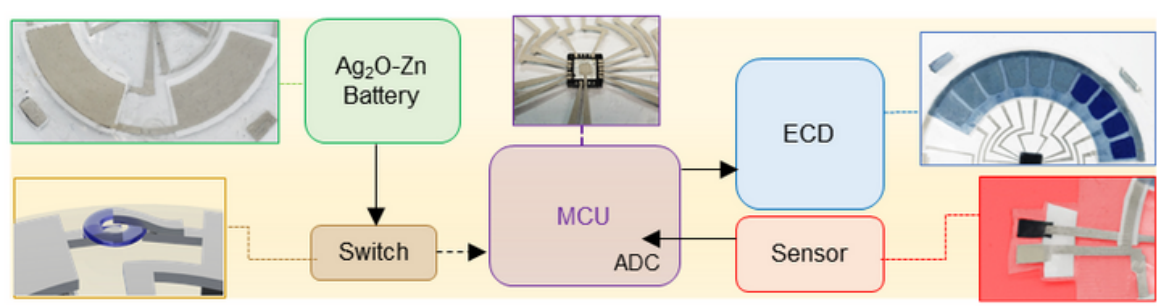

ii

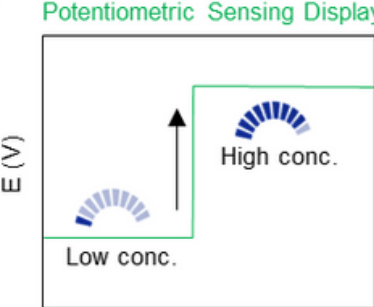

Time (s)

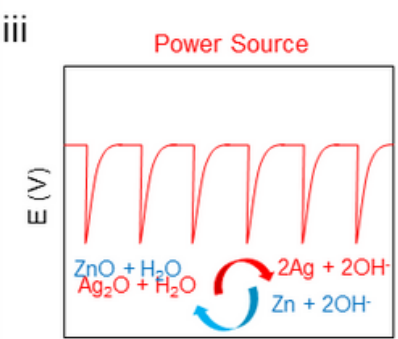

Time (s) ii

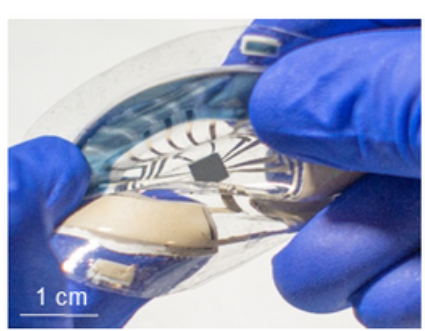

iii

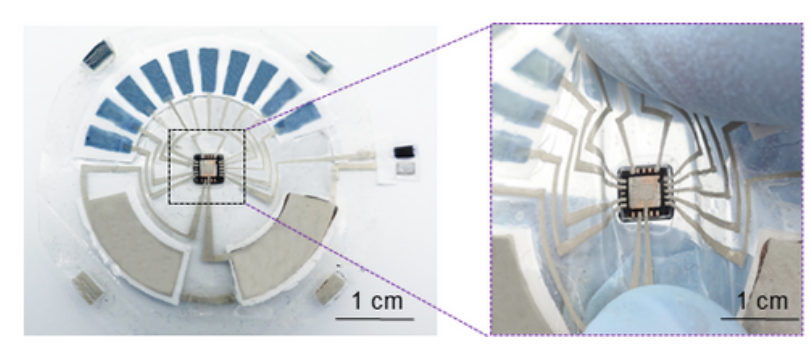

Figure 1

System overview of the all-printed skin interfaced ECD sensing patch. a, Exploded view detailing the individual layers of the epidermal patch. The detailed fabrication procedures are provided in the Supporting Information. b, System flow chart of the system and the zoom-in view of the individual modules. c, The operation of the patch: (i) Photographic image demonstrates the patch used for epidermal sweat sensing by revealing instantaneously the target concentration. (ii) Illustration of the change in the display that changes with the electrolyte concentration and readout of the potentiometric sensor, and (iii) the intermittent discharge mode of the $\mathrm{Ag}_{2} \mathrm{O}-\mathrm{Zn}$ battery that supplies power to the system. d, Photographic images demonstrating the mechanical performance and durability of the patch, including its (i) bending or (ii) stretching, and (iii) stretching of the connection between the interconnect and the MCU. 
a
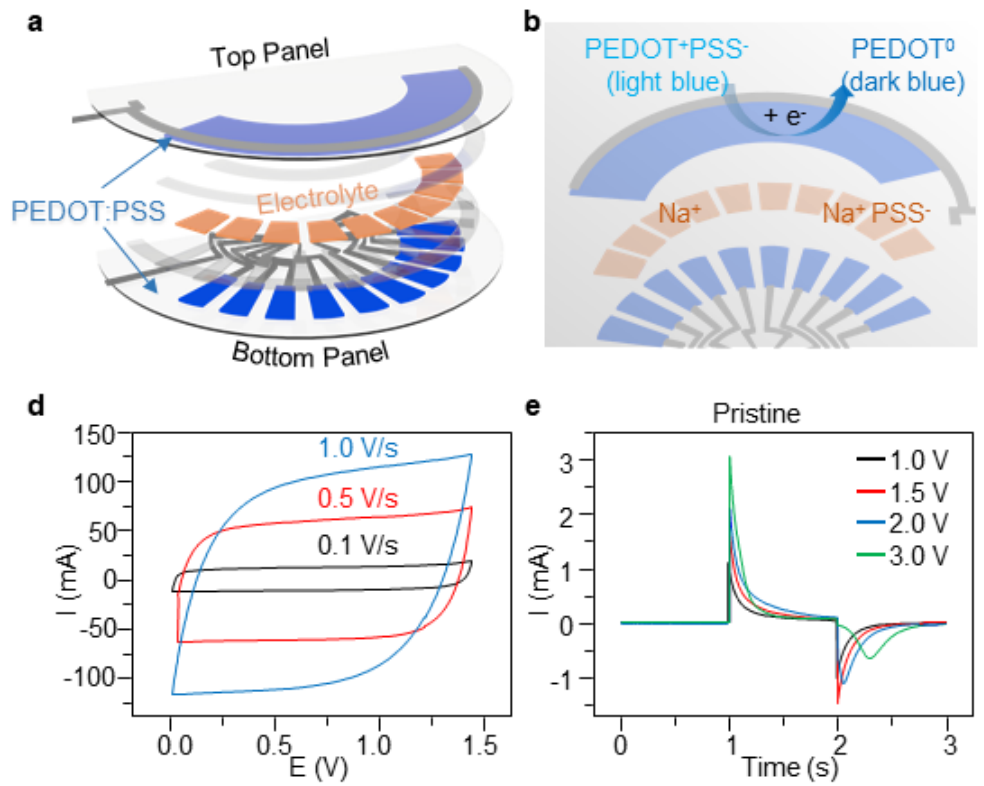

h i

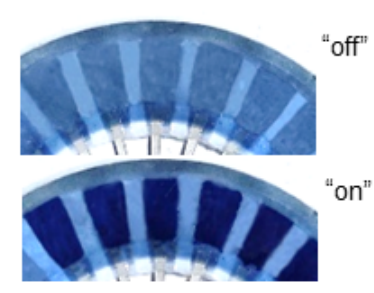

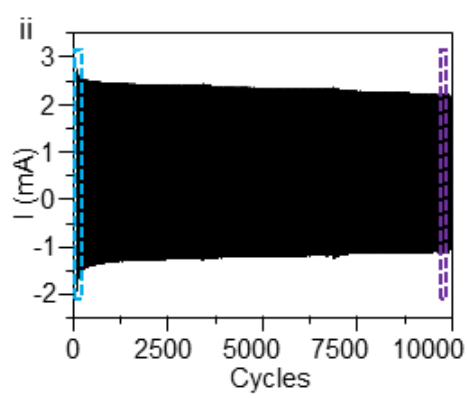
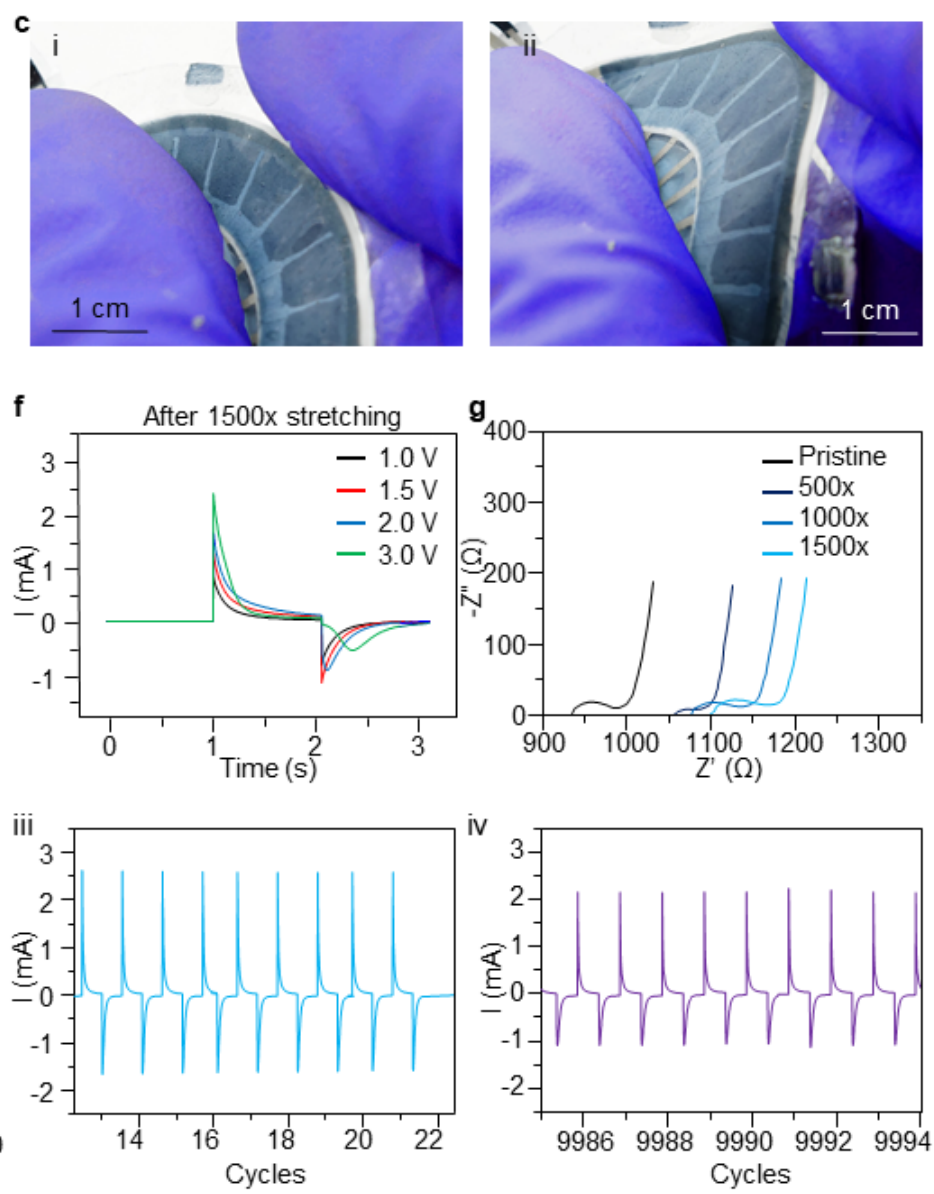

Figure 2

Characterization of the electrochromic display. $\mathbf{a}$, Exploded view of individual layers of the ECD display. $\mathbf{b}$, Reaction mechanism of the ECD display. C, Photo images of ECD display before (i) and during (ii) stretching. d, CV of an ECD pixel at increasing scan rates of 0.1-1 V s $\mathbf{s}^{-1}$. e, The turn-on and turn-off current for pristine ECD pixel at different voltages. $\mathbf{f}$, The turn-on and turn-off current for ECD pixel at different voltages after 1500 times of stretching. $\mathbf{g}$, The EIS profile of a pixel before and after 500, 1000, and 1500 times of stretching. h, Photo images of the ECD display pixels in "OFF" and "ON" states (i). (ii) The stability of current profile of the ECD pixel with turn-on and turn-off for 10000 cycles, (iii-iv) zoom of current fluctuations for the 14-22 cycles (iii) and 9986-9994 cycles (iv). 
a

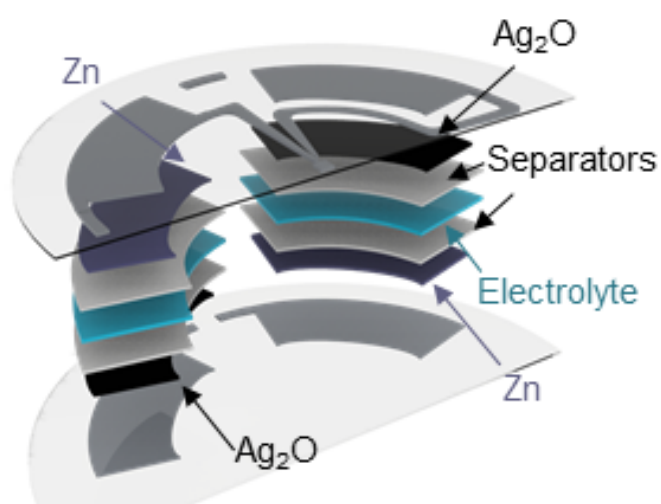

c
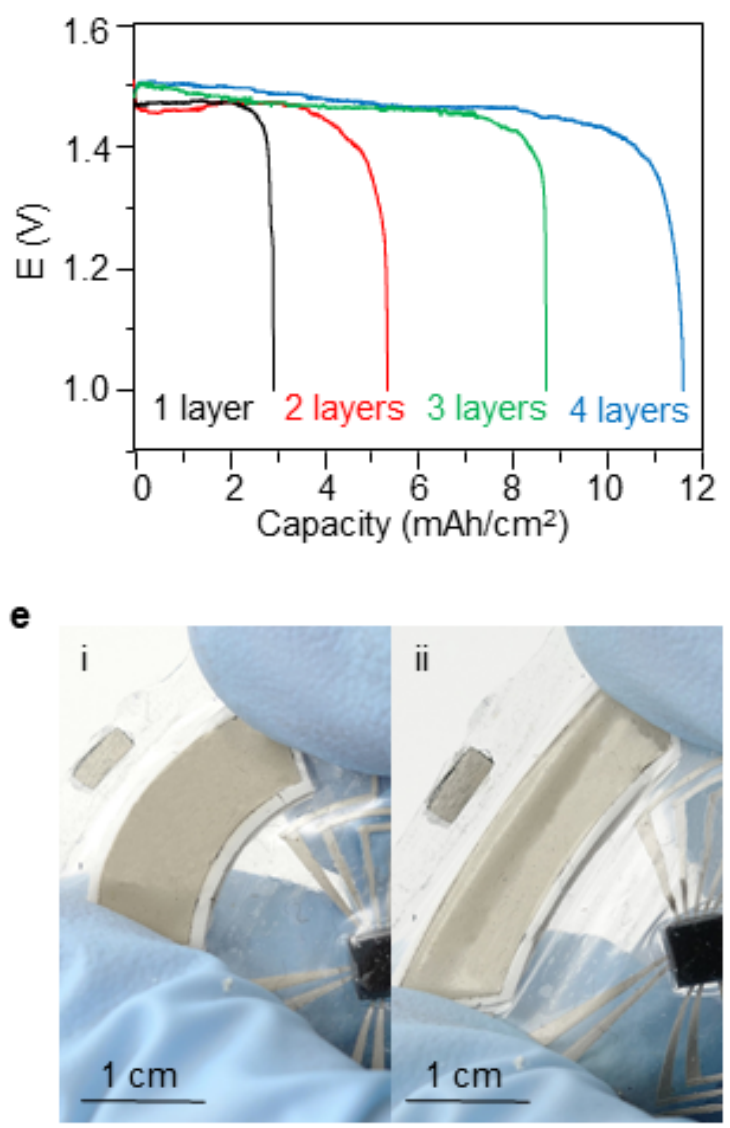

b
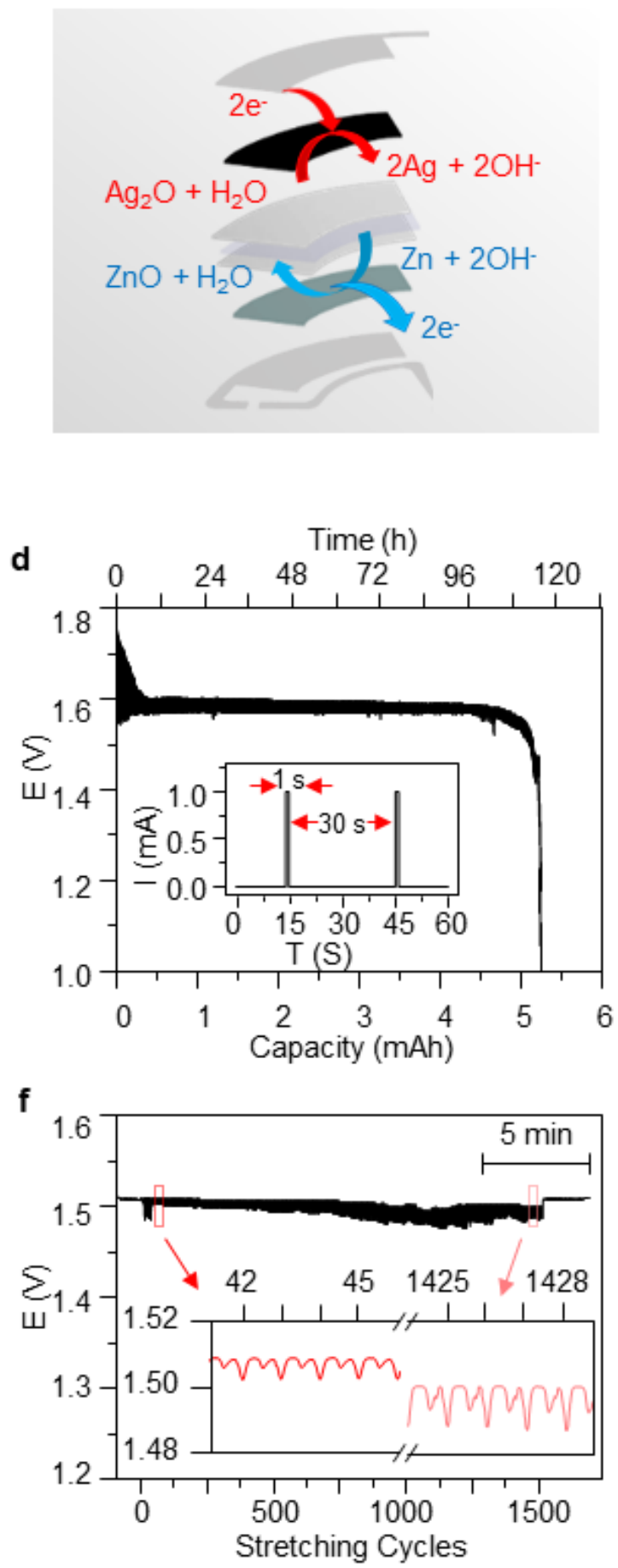

\section{Figure 3}

Characterization of the stretchable battery. a, Exploded view of individual layers of the $\mathrm{Zn} / \mathrm{Ag}_{2} \mathrm{O}$ battery. The detailed fabrication procedures are provided in the Supporting Information. $\mathbf{b}$, Anode and cathode reaction mechanisms of $\mathrm{Zn} / \mathrm{Ag}_{2} \mathrm{O}$ battery. $\mathbf{c}$, Constant $1 \mathrm{~mA}$ discharge of the printed battery with different cathode thicknesses. $\mathbf{d}$, The stability of the potential profile of battery discharge at $1 \mathrm{~mA} \mathrm{~cm}{ }^{-2}$ during 108 h with a 30 s resting time. e, Photo images of the battery before (i) and during (ii) stretching. $f$, Stability of 
potential profile of battery discharge at $1 \mathrm{~mA} \mathrm{~cm}^{-2}$ for 1500 stretching cycles and (inset) discharge-selfcharging curves.

a

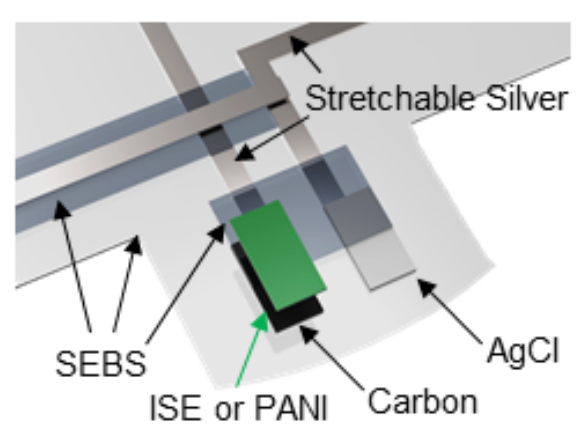

C

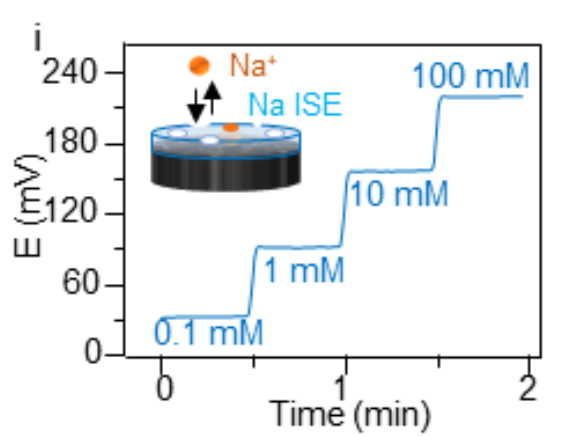

d
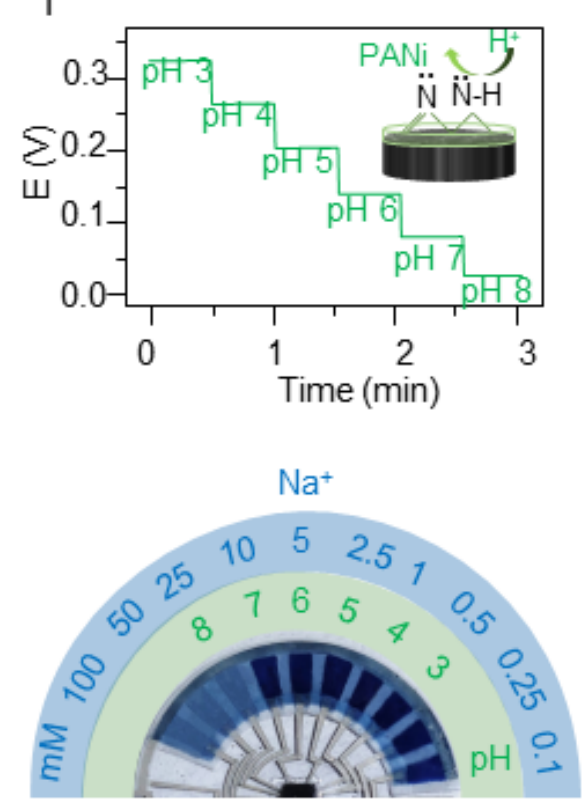

b
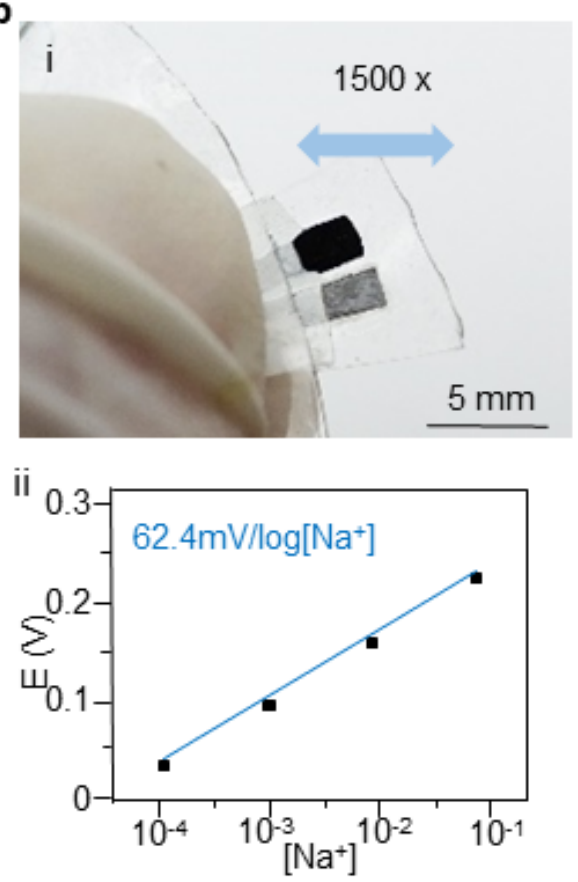

ii

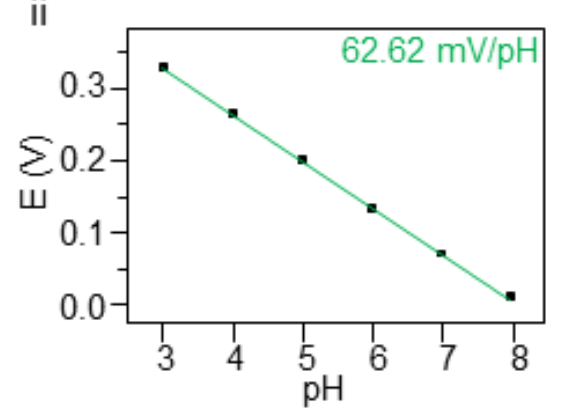

f

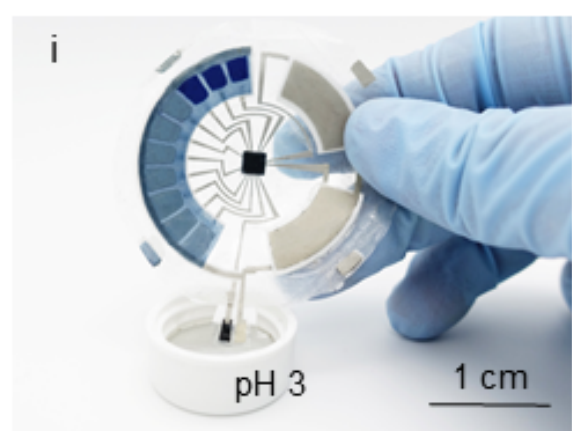

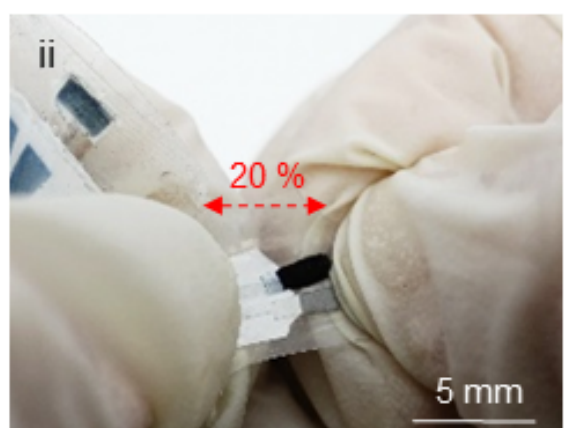
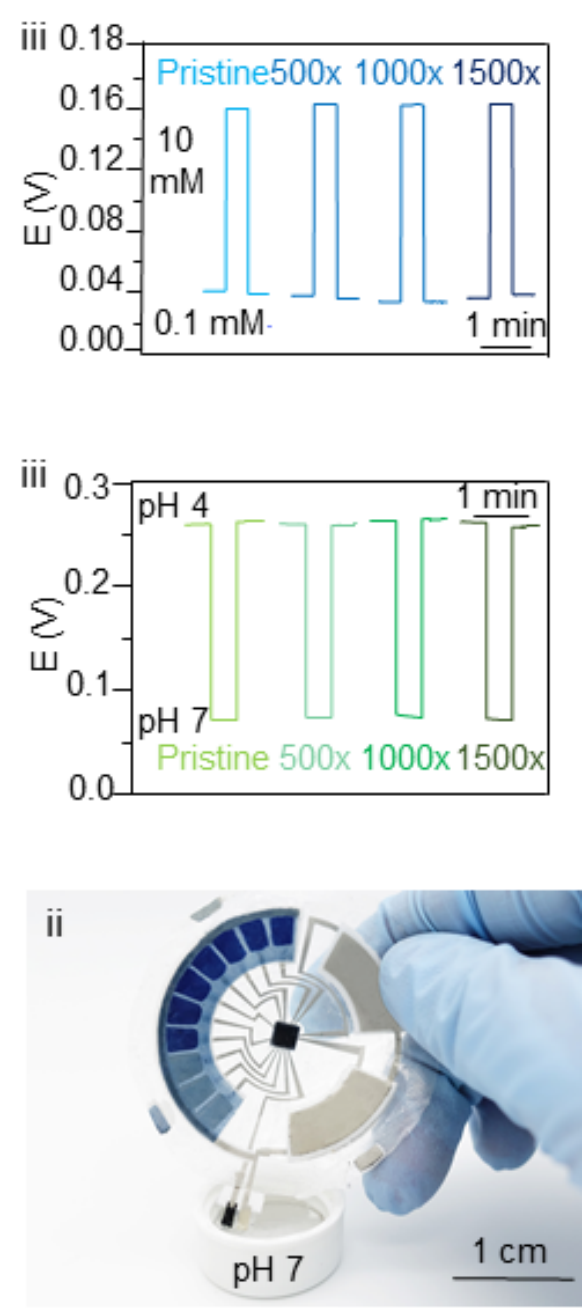

Figure 4 
The device operation for potentiometric $\mathrm{pH}$ and $\mathrm{Na}^{+}$ion sensing. a, Exploded view of individual layers of the potentiometric sensors. b, Photo images of the pH sensor (i) before and (ii) during $20 \%$ stretching. C, (i) Potentiometric signal obtained in $0.1 \mathrm{M}$ PBS pH 7.4 upon changing the $\mathrm{Na}^{+}$concentration and schematic illustration of the $\mathrm{Na}^{+}$sensor. (ii) The corresponding calibration plot of the $\mathrm{Na}^{+}$sensor. (iii) The open circuit potential response of the $\mathrm{Na}^{+}$sensor in $0.1 \mathrm{mM}$ and $100 \mathrm{mM} \mathrm{NaCl}$ solutions after every 500 times of $20 \%$ stretching. c, (i) Potentiometric signal obtained in $0.1 \mathrm{M}$ PBS and schematic illustration of the $\mathrm{pH}$ sensor. (ii) The corresponding calibration plot of the $\mathrm{pH}$ sensor. (iii) The open circuit potential response of the $\mathrm{pH}$ sensor in solutions of $\mathrm{pH} 4$ and pH 7 after every 500 times of $20 \%$ stretching. $\mathbf{e}$, Illustration of the number of pixels for ECD patch related to the signals of the $\mathrm{pH}$ (green) and $\mathrm{Na}^{+}$(blue) sensors. f, Photos images of the ECD patch reading (i) $\mathrm{pH} 3$ and (ii) $\mathrm{pH} 7$ in $0.5 \mathrm{M} \mathrm{PBS}$. 
a

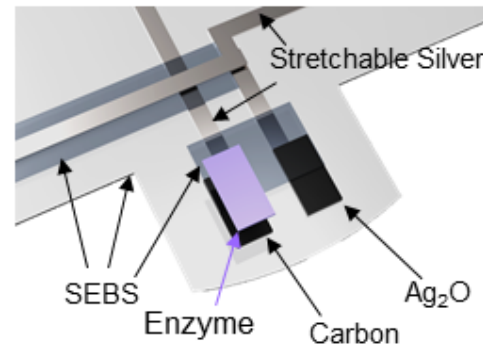

b

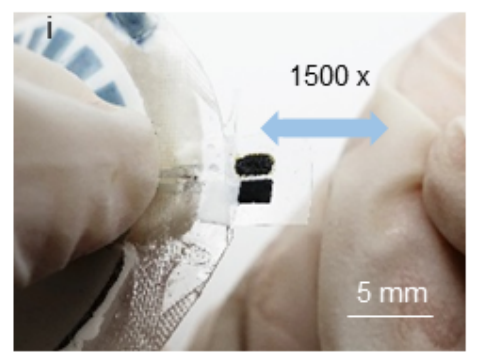

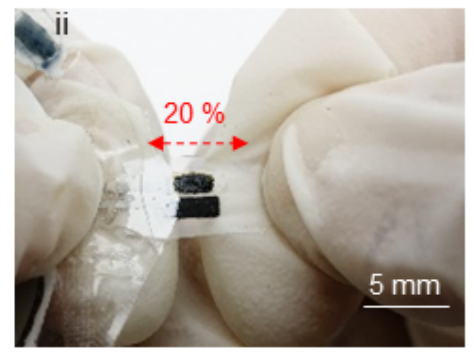

c
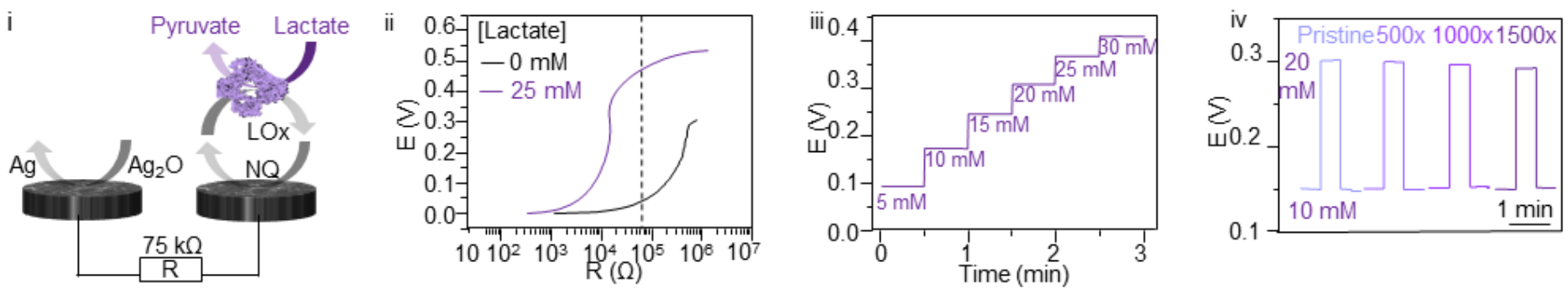

d



e
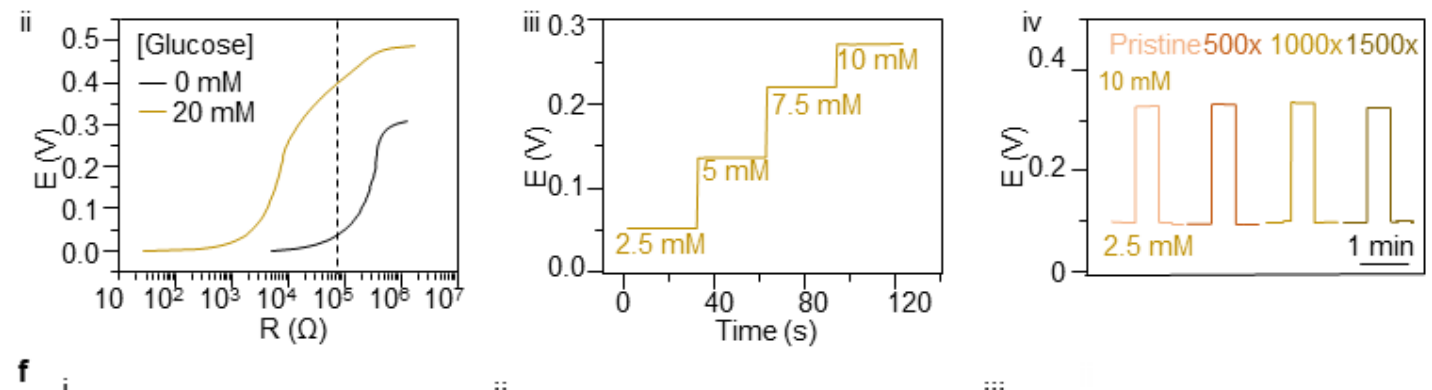

ii

iii
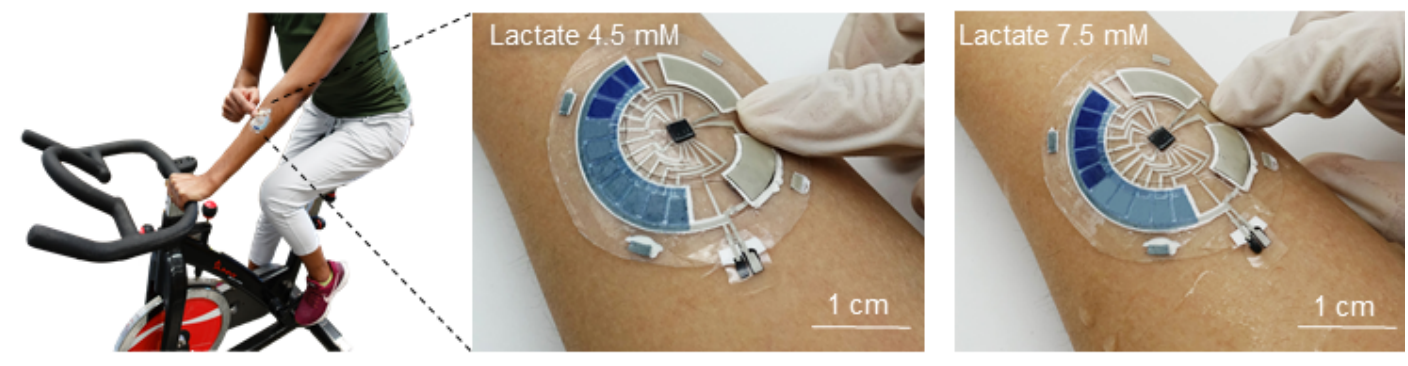

\section{Figure 5}

The device operation for glucose and lactate sensors. a, Exploded view of individual layers of the enzymatic sensors. b, Photo images of the lactate sensor (i) before and (ii) during $20 \%$ stretching. c, (i) Schematic illustration of the sensing mechanism of the lactate sensor. (ii) Linear sweep voltammetry curve for $0 \mathrm{mM}$ and $25 \mathrm{mM}$ lactate, scan rate $1 \mathrm{mV} \mathrm{s}^{-1}$. (iii) Potentiometric signal obtained in $0.1 \mathrm{M}$ PBS $\mathrm{pH} 7.4$, upon increasing the lactate concentration from 5 - $30 \mathrm{mM}$ under $75 \mathrm{k} \Omega$ load. (iv) The open circuit potential response in $2.5 \mathrm{mM}$ and $15 \mathrm{mM}$ lactate after every 500 times of $20 \%$ stretching. d, (i) Schematic illustration of the sensing mechanism of the glucose sensor. (ii) Linear sweep voltammetry curve for 0

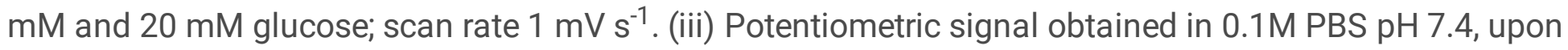
increasing the glucose concentration from 2.5 to $10 \mathrm{mM}$ under $75 \mathrm{k} \Omega$ load. (iv) The open circuit potential 
response in $2.5 \mathrm{mM}$ and $10 \mathrm{mM}$ glucose solutions after every 500 times of $20 \%$ stretching. e, Illustration of the number of pixels for ECD patch related to the signals of lactate (purple) and glucose (yellow) sensors. $f$, (i) On-body lactate sensing by placing the ECD patch on the subject's forearm and displaying $4.5 \mathrm{mM}$ (ii) and $7.5 \mathrm{mM}$ (iii) results by constant-load exercising.

\section{Supplementary Files}

This is a list of supplementary files associated with this preprint. Click to download.

- ECDPatchSupplementaryInfomation.docx

- PatchMovieS11.mp4

- PatchMovieS2.mp4 